\title{
Rare Side Effects of Metronidazole
}

\author{
Venkategowda $\mathrm{PM}^{* 1}$ and Rao $\mathrm{SM}^{2}$ \\ ${ }^{1}$ Department of Critical Care Medicine, Apollo Hospital, Sheshadripuram, Bengaluru, India \\ ${ }^{2}$ Department Of Critical Care Medicine, Yashoda Multi-Speciality Hospital, Somajiguda, Hyderabad, India
}

*Corresponding author: Venkategowda PM, Department of Critical Care Medicine, Apollo Hospital, Sheshadripuram, Bengaluru, 560020. Mobile No: 08897575704, Email: drpradeepmarur@gmail.com

Citation: Venkategowda PM (2017) Rare Side Effects of Metronidazole. SAJ Case Reports 4: 101

Article history: Received: 23 December 2016, Accepted: 12 January 2017, Published: 16 January 2017

Keywords: Metronidazole; Cystitis; Hematuria; Erythematous rash

List of Abbreviations: ICU: Intensive care unit; CT: Computed tomography; CSF: Cerebrospinal fluid; SDH: Subdural hemorrhage;

ADR: adverse drug reactions

\section{Letters to the Editor}

Sir,

Drugs related complications are commonly seen in ICU patients because many of these patients are on treatment with multiple drugs, having multiple comorbids and with or without multi organ dysfunction. Complications are mainly due to altered drug metabolism, altered drug excretion, higher dosage of drug administered or drug to drug interactions [1]. We describe two rare side effects of use of Metronidazole in our ICU patients who got better after stopping this drug.

Case-1

A 24 year old male with history of road traffic accident (sustained multiple head and neck injuries) was referred to our multispecialty hospital from a local hospital after initial stabilization and tracheostomy. On examination, patient was conscious and responding to commands. Initial CT scan of brain showed frontal bone depressive fracture along with underlying contusion of brain. Ultrasonography of abdomen was normal. Patient had CSF rhinorrhoea with suspected bacterial meningitis for which he was started on Vancomycin and Meropenem. He also received Metronidazole injection (IV) in view of suspected wound infection from anaerobic organism. On seventh day of admission, patient developed hematuria (Figure-1). We suspected that it could be due to cystitis related hematuria or pigmented urine which is the rare side effect of Metronidazole. The routine urine microscopy showed multiple RBC's and repeat ultrasonography of abdomen was also normal with normal platelets and coagulation parameters. It was suspected that cystitis was probably due to a rare side effect of Metronidazole and hence it was stopped. The next day urine became clear (Figure-2) and patient recovered from hematuria.

\section{Case-2}

A 60 years old male patient with history of road traffic accident (sustained head injury) came to our multispecialty hospital. On examination, patient was drowsy and arousable. CT scan of brain showed left parietal bone depressive fracture along with small SDH (Subdural Hemorrhage). He was treated with injection Metronidazole in view of suspected contaminated wound (By anaerobic organism). On third day patient had developed diffuse Erythematous rashes over left leg (Figure-3). We suspected it could be drug induced Erythematous lesion and hence injection Metronidazole was stopped. Later these rashes disappeared.

Metronidazole is a synthetic nitroimidazole. It acts by disruption of DNA and inhibition of nucleic acid synthesis. It is bactericidal against many anaerobic gram negative bacilli, anaerobic gram positive cocci and many pathogenic protozoa. It is metabolized in liver (Hydroxylation, oxidation and glucuronic conjugation) and excreted in urine (75\%) and faeces (25\%). The complications related to Metronidazole are many but rare. Table-1 shows about complications of the Metronidazole. Oral or IV administration of Metronidazole can produce dark or reddish brown color of urine. It is due to presence of water soluble pigment formed during metabolism of Metronidazole. Rarely Metronidazole produces hematuria due to cystitis [2]. This usually resolves after stopping the drug as we did in our first patient. 


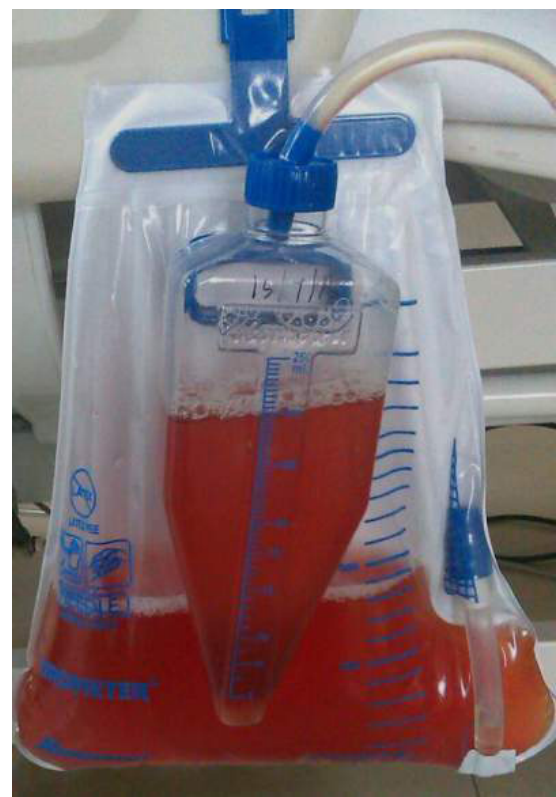

Figure 1: Showing hematuria following administration of intravenous Metronidazole

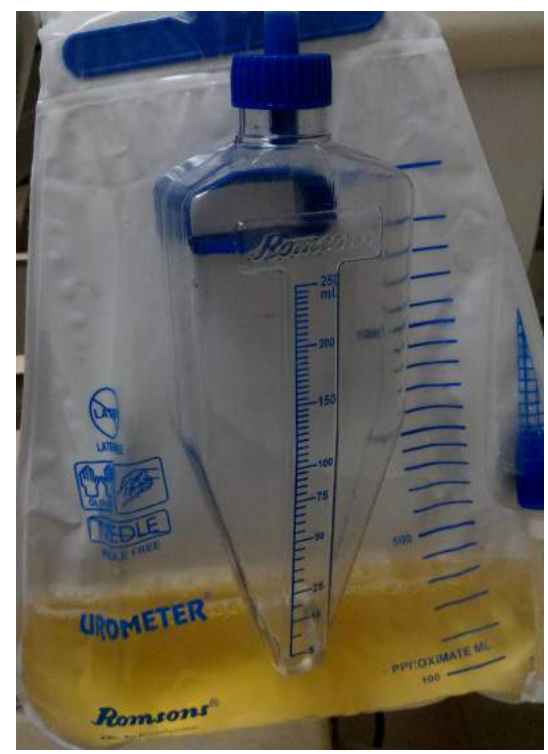

Figure 2: Showing clear urine after stopping Metronidazole treatment

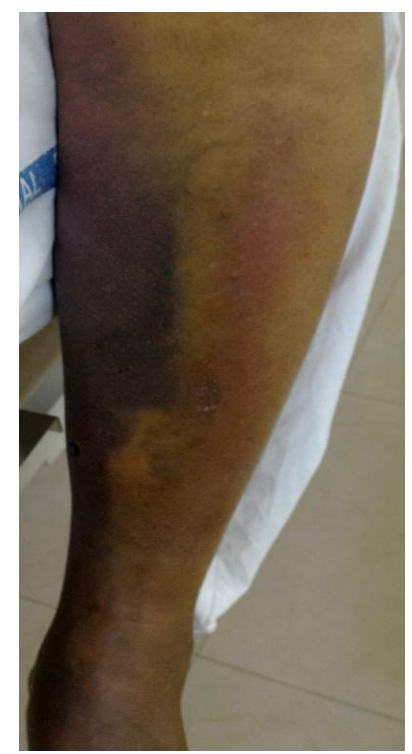

Figure 3: Diffuse Erythematous rashes over left leg due to intravenous Metronidazole treatment 


\begin{tabular}{|c|c|}
\hline Systems Involved & Side Effects \\
\hline $\begin{array}{l}\text { Central Nervous } \\
\text { System }\end{array}$ & $\begin{array}{c}\text { Convulsion, Encephalopathy, Aseptic meningitis, Optic and Peripheral } \\
\text { neuropathy. }\end{array}$ \\
\hline $\begin{array}{l}\text { Gastro Intestinal } \\
\text { System }\end{array}$ & $\begin{array}{c}\text { Anorexia, Nausea and vomiting. Oral mucositis, Pancreatitis, and } \\
\text { Pseudo membreneous colitis. }\end{array}$ \\
\hline Urogenital System & Darkened urine, Dysuria, Cystitis and rarely Hematuria. \\
\hline Dermatological & $\begin{array}{l}\text { Pruritis, Urticaria, Erythematous rashes, Stevens-Johnson Syndrome, } \\
\text { Toxic Epidermal necrolysis. Angioedema and Anaphylactic shock. }\end{array}$ \\
\hline Hematological system & Transient leucopenia, Agranulocytosis, Bone marrow aplasia. \\
\hline Cardio Vascular & Prolonged QT interval. \\
\hline
\end{tabular}

Table 1: Showing side effects of Metronidazole

Cutaneous drug eruptions due to drugs are seen in 2-3\% of hospitalized patients. Metronidazole can rarely produce Pruritis, Urticaria, Erythematous rashes and Stevens - Johnson syndrome during the course of treatment [3]. Topical corticosteroids along with stoppage of drugs can reduce the intensity of these reactions.

Drug related complications can increase morbidity and mortality if they are not diagnosed and treated in time. Naranjo et al have recommended a scale (0-10 points) which can predict the probability of adverse drug reaction (ADR) [9-10 = definite ADR, 5-8= probable ADR, $1-4=$ possible ADR and $0=$ doubtful ADR]. In our observation, the score was 5 (Probable ADR) [4]. Since there is no such case report published and only 2 cases observed it is difficult to do the risk assessment of the outcome and requires large observational study to tell Metronidazole as definite cause of hematuria and Erythematous rash. Metronidazole which is commonly used in the treatment of anaerobic infection is not without any side effects. High level of suspicion for any rare side effects and timely stopping of drug is only required to treat many of these complications.

\section{Acknowledgements}

We acknowledge management of the hospital for their valuable support.

\section{References}

1. Darchy B, Le Miere E, Figueredo B, Bavoux E, Domart Y., et al. (1999) Iatrogenic Diseases as a Reason for Admission to the Intensive Care Unit: Incidence, Causes, and Consequences. Arch Intern Med 159: 71-8.

2. Lihua L, Hua W and Xiaodan S (2011) Hematuria induced by oral metronidazole in two patients. Adverse drug reactions $\mathrm{j} 01$.

3. Crowson AN, Brown TJ and Magro CM (2003) Progress in the understanding of the pathology and pathogenesis of cutaneous drug eruptions. Am J Clin Dermatol 4: 407-28.

4. Naranjo CA, Busto U, Sellers EM, Sandor P, Ruiz I, Roberts EA., et al (1981) A method for estimating the probability of adverse drug reactions. Clin Pharmacol Ther 30: 239-45. 